\title{
Rethinking therapeutic and recreational nicotine products: a commentary on Hatsukami et al
}

\author{
Ron Borland ${ }^{1}$ Coral Gartner ${ }^{2}$
}

The paper by Hatsukami et $a l^{1}$ in this issue of the journal shows that nicotine gum is at least as effective as snus as a cessation treatment. This result may surprise many, especially those exploring additional benefits of low-toxin tobacco products over pure nicotine as cessation aids. We think it raises two important issues: First, that a product containing only medicinal nicotine could do at least as well as a product with all the attributes of tobacco strongly suggests that the other ingredients in tobacco, such as minor alkaloids, that many have hypothesised as being important may not play much if any role in treating nicotine dependence.

The second issue arises from the finding that there was more continued (longer term) use of snus even though it was not rated as potent in quelling cravings. This finding mirrors the situation in Scandinavia where snus use is widespread, but nicotine gum is primarily used for cessation. Why is snus preferred if the medicinal product is just as good or even better at quelling withdrawal? We think it likely that the promotion of snus as a consumer product (and a tobacco product at that) compared with promotion of nicotine gum as a medicine helps explain the findings of the Hatsukami et al study, and more generally, why these medicinal products have failed to excite widespread consumer interest as long-term substitutes for smoking. The market success of ecigarettes, which have overtaken medicinal nicotine sales in the $\mathrm{UK}^{2}{ }^{2}$ provides another example of a nicotine product marketed as a consumer good proving more popular than medicinal products with the same active ingredient.

We know that the way people think about a product influences how they approach it, whether they try it, the experiences they expect from it and their

\footnotetext{
${ }^{1}$ Cancer Council Victoria, Melbourne, Victoria, Australia; ${ }^{2}$ The University of Queensland, School of Public Health, Herston, Queensland, Australia
}

Correspondence to Dr Ron Borland, Cancer Council Victoria, Melbourne VIC 3004, Australia; Ron.Borland@cancervic.org.au likelihood of continuing to use it. ${ }^{3}$ Expectancies have been shown experimentally to override the direct effects of nicotine. ${ }^{4}$ Thus it is reasonable to assume that users' expectancies of the intended function of a product might also influence both how they experience and use it. These expectancies can be set up by the way the product is packaged and marketed.

Most medicines are designed to be used short term, and any initial aversiveness needs to be tolerated or masked. For medicinal nicotine products, their role is to reduce or eliminate the desire to smoke and it is expected that this will only be needed for a short period of time. By contrast, a recreational product like snus is used for the experiences it generates, so persisting use is always a possibility. It seems likely that some of the initial aversive experiences of use which initially discourage continuation, can become conditioned stimuli for the rewards of the experiential effects of the nicotine, and thus may support longer term use. This can also happen for medicinal nicotine products, ${ }^{5}$ not just recreational forms of nicotine.

We may need to move beyond a simple medical model if we are to maximise the speed with which we move existing smokers away from tobacco cigarettes. It is likely that stronger marketplace incentives that encourage switching to less-harmful nicotine sources such as large price differences between smoked tobacco and recreational clean nicotine products, wider availability and restrained promotion carefully targeted at smokers (eg, promotional material provided with cigarette purchases) could encourage switching. Along with this there is a need for consumer regulations to ensure the products are as safe (low in harm) as possible. Factors such as these likely contributed to the reinvigoration of the snus market in Sweden in the 1970s and 1980s. ${ }^{6}$ This approach to promoting alternative products should be limited to ways that minimise uptake by young people.

There is a need for those in public health to look rationally at the potential of a market-based solution and to also accept that the potential of products is partly determined by how people think about them. This requires a biopsychosocial approach, not a separate focus on either social determinants or on the biological pull of nicotine.

This conceptualisation implies that the efficacy-oriented approach to medicines is far too limited in this area, we need broader evaluation frameworks that incorporate both ease of encouraging use and efficacy when used. Ultimately if clean nicotine products get people off smoking it is a desirable outcome regardless of whether the smoker sees this as a therapeutic process or simply a consumer choice of switching to a less harmful alternative.

Contributors Commentary conceived by both authors. RB prepared first draft, CG commented and added new material. Final version agreed on by both the authors.

Competing interests None declared.

Provenance and peer review Commissioned; internally peer reviewed.

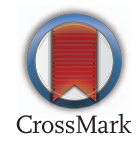

To cite Borland R, Gartner C. Tob Control 2016;25:245.

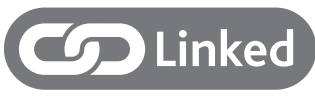

- http://dx.doi.org/10.1136/tobaccocontrol-2014052080

Tob Control 2016;25:245

doi:10.1136/tobaccocontrol-2015-052388

\section{REFERENCES}

1 Hatsukami D, Severson H, Anderson A, et al. Randomized clinical trial of snus vs. medicinal nicotine among smokers interested in product switching. Tob Control 2016;25:267-74.

2 West R, Beard E, Brown J. Trends in electronic cigarette use in England STS140122; University College London 23/04/2015. http://www. smokinginengland.info/latest-statistics

3 Borland R. Understanding hard to maintain behaviour change: a dual-process approach. Oxford: Blackwell-Wiley, 2014.

4 Gu X, Lohrenz T, Salas R, et al. Belief about nicotine selectively modulates value and reward prediction error signals in smokers. Proc Natl Acad Sci USA 2015; 112:2539-44.

5 Frankel T. The mysterious nicotine lozenge that ex-smokers are hoarding. The Washington Post 9 Feb 2015. http://www.washingtonpost.com/business/ economy/the-mysterious-nicotine-lozenge-that-exsmokers-are-hoarding/2015/02/09/2b8d19c6-ae3711e4-abe8-e1ef60ca26de_story.html

6 Gartner CE, Hall WD, McNeill A. Chapter 9: harm reduction policies for tobacco. In: Rhodes $T_{1}$ Hedrich D, eds. Harm reduction: evidence, impacts and challenges. Lisbon: EMCDDA, 2010: 255-73. 